Dossier

El conflicto saharaui y la cultura de la resistencia

Coordinado por Mustapha M-Lamin Ahmed

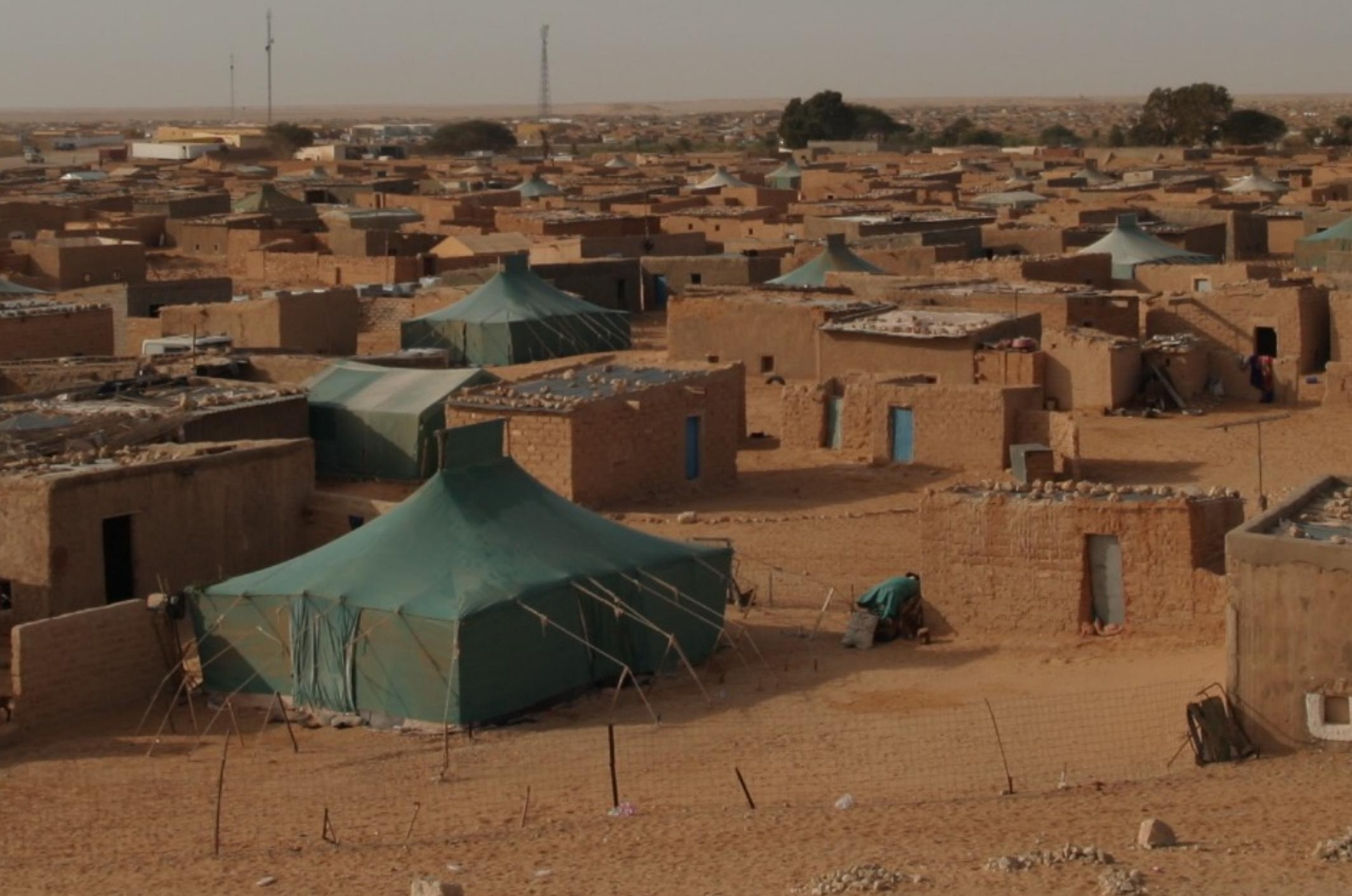


Dossier

\section{El conflicto saharaui y la cultura de la resistencia}

Coordinado por MUSTAPHA M-LAMIN AHMED · musmola@alumni.uv.es

UNIVERSiDAD DE TIFARITI (SÁHARA OCGIDENTAL) / UNIVERSiTAT DE VALÈNCIA (ESPAÑa)

Este dossier quiere contribuir a darle presencia al conflicto saharaui en el ámbito del análisis cultural y académico. La relación del estado español con la cuestión saharaui tiene sus raíces en los lazos históricos de la metrópoli sobre su antigua colonia, pero sobre todo por su responsabilidad histórica en una descolonización irresponsable en la que, poco antes de su precipitada salida del territorio, se entregó el pueblo saharaui a Marruecos y Mauritania. Kamchatka, Revista de análisis cultural, presta su espacio de debate para permitir que desde diferentes ángulos se puedan realizar distintas aproximaciones a la realidad saharaui. Es de especial importancia, en este caso, poner el acento en la importancia que para el pueblo saharaui tiene destacar su cultura como un rasgo más de su resistencia frente a la amenaza marroquí de aculturación o de eliminación directa de su identidad.

Carmen Gómez analiza la organización política y social de los saharauis en España, poniendo en contexto la articulación de colectivos, luchas y prácticas culturales en la comunidad saharui en su antigua metrópoli. En torno a la violencia represiva del estado marroquí contra el pueblo saharui contamos con un artículo de Mustapha M-Lamin Ahmed, que analiza los testimonios de víctimas directas de prisiones secretas marroquíes y de supervivientes de bombardeos de la aviación marroquí. Esa contribución se complementa con el testimonio inédito de Sid Ahmed Hnini, que relata su experiencia en las prisiones marroquíes como prisionero de guerra tras 12 años de cautiverio, de 1984 a 1996. La publicación de su testimonio reviste una gran importancia histórica, cuando se cumplen veinte años de la puesta en libertad de Sid Ahmed Hnini y otros 65 ex-prisioneros de guerra saharauis, el llamado grupo de los 66, que soportaron toda suerte de chantajes y presiones para cambiar de bando o rendirse y se mantuvieron en resistencia hasta su puesta en libertad.

Para examinar la relación histórica entre España y el Sáhara, José Martínez Rubio analiza las controversias entre intelectuales de izquierdas en los primeros años del conflicto saharaui, el grado de presencia mediático del conflicto saharaui en la prensa española y su relación con el debate de la memoria histórica. Larosi Haidar, especialista en lingüística y traducción, analiza algunos 
‘intraducibles culturales’ relacionados con accidentes y realidades geográficas del Sáhara, y de difícil traducción al español.

El dossier se cierra con una breve antología de poemas inéditos escritos por tres poetas saharauis que escriben en español. Limam Boicha y Saleh Abdalahi están vinculados al grupo conocido como Generación de la Amistad, mientras que Sidi M. Talebbuia es un joven abogado saharaui afincado en Madrid que trata de hacer visible sus creaciones. La poesía saharaui escrita en español es una manifestación cultural prácticamente desconocida, ya sea en España, o en el Sáhara; en el primer caso debido a la rigidez del canon literario, donde la poesía ocupa un lugar casi marginal; mientras que en el segundo caso, en el Sáhara, la poesía tradicional oral, recitada en público, sigue ocupando el centro de las manifestaciones culturales del pueblo saharaui, por lo que resulta difícil medirse en aceptación con esa arraigada tradición poética en el Sáhara Occidental. Resulta interesante, no obstante, este fenómeno de creadores que usan la lengua del antiguo colonizador como vehículo no ya de expresión, sino de manifestación artística. 